\title{
Childhood maltreatment and self-harm in Chinese adolescents: moderation and mediation via resilience
}

Xin Tian ${ }^{1,2 \dagger}$, Jin Lü ${ }^{2,3 \dagger}$, Yusan Che ${ }^{1}$, Die Fang ${ }^{1}$, Hailiang Ran ${ }^{1}$, Xingting $\mathrm{He}^{4}$, Yanjiao Wang ${ }^{2}$, Tianlan Wang ${ }^{4}$, Xiufeng $\mathrm{Xu}^{2}$, Guangya Yang ${ }^{4}$ and Yuanyuan Xiao ${ }^{1 *}$ (i)

\begin{abstract}
Background: Published studies examining the association between childhood maltreatment (CM) and self-harm (SH) among adolescents have been accumulated. It is possible that resilience serves as a moderator or mediator in CM-SH association, nevertheless, this topic has never been thoroughly investigated.

Methods: In this population-based cross-sectional study, we surveyed 3146 students aged 10-17 in southwest China. The Childhood Trauma Questionnaire (CTQ), the Modified version of Adolescents Self-Harm Scale (MASHS), and the Resilience Scale for Chinese Adolescents (RSCA) were used to measure CM, SH, and resilience. Correlational analyses, hierarchical multivariate linear regression, and structural equation modeling (SEM) were performed to test the moderation and mediation of resilience in CM-SH association.

Results: Findings revealed that, resilience with its five dimensions, CM, and SH were significantly correlated with each other. Resilience partially moderated and mediated the association between CM and SH. Besides, among all dimensions of resilience, emotion regulation, interpersonal assistance, and family support presented the strongest mediation in CM-SH association.

Conclusions: Our results highlight the importance of resilience in CM related SH among Chinese teenagers. Resilience-oriented intervention could be considered in SH intervention measures for adolescents who had experienced $\mathrm{CM}$.
\end{abstract}

Keywords: Childhood maltreatment, Self-harm behaviors, Resilience, Emotion regulation, Family support, Interpersonal assistance

\footnotetext{
* Correspondence: 33225647@qq.com

${ }^{+}$Xin Tian and Jin Lu contributed equally to this work.

${ }^{1}$ Department of Epidemiology and Health Statistics, School of Public Health,

Kunming Medical University, Kunming 650500, Yunnan, China

Full list of author information is available at the end of the article
}

(c) The Author(s). 2021 Open Access This article is licensed under a Creative Commons Attribution 4.0 International License, which permits use, sharing, adaptation, distribution and reproduction in any medium or format, as long as you give appropriate credit to the original author(s) and the source, provide a link to the Creative Commons licence, and indicate if changes were made. The images or other third party material in this article are included in the article's Creative Commons licence, unless indicated otherwise in a credit line to the material. If material is not included in the article's Creative Commons licence and your intended use is not permitted by statutory regulation or exceeds the permitted use, you will need to obtain permission directly from the copyright holder. To view a copy of this licence, visit http://creativecommons.org/licenses/by/4.0/. The Creative Commons Public Domain Dedication waiver (http://creativecommons.org/publicdomain/zero/1.0/) applies to the data made available in this article, unless otherwise stated in a credit line to the data. 


\section{Background}

Childhood maltreatment (CM) is physical, sexual, psychological abuse or neglect of children, especially by parent(s) or caregiver(s). CM has been identified as a major public health issue. It is reported that each year, $4-16 \%$ and $5-10 \%$ of children are physically and sexually abused, and one-tenth of children suffered from emotional abuse or neglect by their parents [1]. CM is also prevalent in China: a single site survey of 7702 participants revealed that, for children under 16 years old, a staggering $31.1 \%$ reported had been abused [2]. CM can impose multiple detrimental impacts on the victims, from deficits in educational achievement, mental problems (such as depression, anxiety, post-traumatic stress symptoms), to low self-esteem, dissociation, and personality disorders, all of which can persist into the adulthood $[1,3]$.

Self-harm (SH) normally defined as intentional, direct destruction of body tissue, with or without suicidal intent [4]. Although it can occur within any period of life, a higher prevalence has been found in pubertal age [5]. $\mathrm{SH}$ has long been considered a major problem among youths [6], affecting 17\% of those aged between 12 and 18 years in China [7]. Though non-fatal, SH always indicative of tragic outcomes: it has been repeatedly verified as the strongest indicator of future suicide [8]. Besides, following the index episode of $\mathrm{SH}$, self-injurers are inclined to develop repeated and frequent $\mathrm{SH}$, and about $2-7 \%$ of them will commit suicide in the following years $[9,10]$.

Among all adverse psychosocial factors, $\mathrm{CM}$ has been linked to elevated risk of $\mathrm{SH}$ in adolescents [11]. Given the fact that, $\mathrm{CM}$ can increase not only the risk of $\mathrm{SH}$ but also the probability of suicidal behaviors [12], CM related $\mathrm{SH}$ in youths should be effectively intervened. Except for direct measures on preventing CM in general, interventions which targeting on crucial mediators or moderators in CM-SH association can also be considered. Resilience is gradually attracting attention in the recent years, especially among children and adolescents. It reflects the ability to well adapt the adversities [13]. It has been found that resilient individuals tended to report decreased risk in negative consequences (like depression, anxiety) after exposed to CM [14]. Similarly, a higher level of resilience was related to lower risk of internalizing problems [15]. Therefore, it is reasonable to postulate that resilience may also protect against $\mathrm{SH}$ among adolescents who had experienced CM [16]. Also, a meta-analysis concluded that, the detrimental effect of $\mathrm{CM}$ can be moderated or even averted under the premise of effectively consolidated resilience of the victims [14]. Therefore, we put forward the assumption that, resilience plays a prominent role in $\mathrm{CM}-\mathrm{SH}$ association, possibly as a mediator, or a moderator, or both.
Nevertheless, no published studies have investigated this assumption so far.

In this cross-sectional study, we intended to discuss this issue in a large representative sample of Chinese adolescents. We tested the hypothesized mediation and moderation of resilience in the association between $\mathrm{CM}$ and $\mathrm{SH}$.

\section{Method}

\section{Participants}

Participants in this cross-sectional study were recruited from 14 schools (5 primary schools, 5 junior middle schools, and 4 high schools) in Lincang, Yunnan, China, from December 1 to 13, 2019. A three-stage random clustering sampling method was applied in the present survey: In stage one, we randomly chose Linxiang district out from 8 prefectures and districts within Lincang's jurisdiction; in stage two, 14 schools in Linxiang district were randomly determined; in stage three, all eligible students (aged 10-17) from 3 to 4 randomly selected classes within each chosen school were initially included.

\section{Measurements}

Each participant was invited to fill a self-administered questionnaire that contains demographics, $\mathrm{CM}$, resilience, $\mathrm{SH}$, bullying, negative life events, etc. Only the former four parts were analyzed in the present study. Prior to the survey, informed consents from the participants and their legal guardians were obtained. This study was approved by the Ethics Committee of The Third People's Hospital of Lincang (Lincang Psychiatry Hospital).

\section{Childhood maltreatment}

The brief version of Childhood Trauma Questionnaire (CTQ) is comprised of 28 questions [17], and can be divided into five subscales, measuring three types of abuse (physical, sexual, emotional) and two types of neglect (emotional and physical). A 5-point Likert scale was used to gauge the frequency of maltreatment. The Cronbach's a for CTQ in the present study was 0.81 (Bootstrap 95\% CI: 0.80-0.83). The authors had received permission to use the questionnaire.

\section{Resilience}

The Resilience Scale for Chinese Adolescents (RSCA) is a 28-item instrument [18], assessing five dimensions of resilience (goal concentration, interpersonal assistance, emotion regulation, family support, and positive perception). Answers to each question are 5point Likert style, from "completely disagree" (with assigned score of 1) to "completely agree" (with assigned score of 5). A higher combined score of RSCA as well as its five dimensions indicate a better 
resilience in general or in specific aspect. The Cronbach's a of the RSCA in the present study was 0.86 (Bootstrap 95\% CI: 0.85-0.87). The authors had received permission to use the questionnaire.

\section{SH}

The Modified version of Adolescents Self-Harm Scale (MASHS) simultaneously evaluating the frequency and severity of the 18 most commonly seen SH behaviors in Chinese adolescents [19]. Response categories for frequency and severity were from "never" (with assigned score of 1) to "higher than five times" (with assigned score of 4) and from "non-perceptible injury" (with assigned score of 1) to "extremely critical injury" (with assigned score of 5). The authors had received permission to use the questionnaire.

\section{Data analytic procedure}

The demographic and psychometric variables were summarized using descriptive statistics. A Pearson correlation matrix between $\mathrm{CM}$ (CTQ), resilience with its five dimensions (RSCA), and SH score (MASHS) was then conducted to examine pairwise correlations. After centering scores of CTQ, RSCA, and MASHS, a series of hierarchical regression models which controlled for significant demographics identified in univariate analysis were fitted: $\mathrm{SH}$ score was taken as the dependent variable, the adjusted association between $\mathrm{CM}$ and $\mathrm{SH}$, resilience and $\mathrm{SH}$ were estimated, besides, the product term of CM and resilience was finally incorporated to explore the moderating effect of resilience in $\mathrm{CM}-\mathrm{SH}$ association. Finally, two path models were established to test for the mediation of resilience as well as its five dimensions.

All analyses were executed by using the $\mathrm{R}$ software (Version 3.6.2, The R Foundation for Statistical Computing, Vienna, Austria). The "survey" and "lavaan.survey" packages were used to recalibrate the unequal sampling weights produced by cluster sampling design.

\section{Results}

\section{Descriptive statistics}

After excluding ineligible participants (failed quality inspection: $N=7$; failed age requirement: $N=88$ ), a total of 3146 were entered into our analyses with an effective response rate of $97.07 \%$. The basic characteristics of the respondents were provided in Table 1: 1480 adolescents endorsed at least one episode of $\mathrm{SH}$, and the lifetime prevalence was $47.07 \%$ (95\% CI: 45.33-48.81\%). The mean scores for MASHS and CTQ were 10.18 (SD = 20.59) and 36.03 ( $\mathrm{SD}=9.59)$, respectively. Regarding to resilience, the average scores of the five dimensions varied from $13.58(\mathrm{SD}=4.13)$ to $22.42(\mathrm{SD}=4.71)$, while the average RSCA score was $95.52(\mathrm{SD}=17.73)$.
Table 1 Demographic characteristics of all study samples $(N=$ 3146)

\begin{tabular}{|c|c|c|}
\hline Factor & $N(\%)$ & Mean $\pm S D$ \\
\hline \multicolumn{3}{|l|}{ Sex } \\
\hline Male & $1437(45.68)$ & \\
\hline Female & $1709(54.32)$ & \\
\hline Age & & $13.32 \pm 2.18$ \\
\hline \multicolumn{3}{|l|}{ Ethinicity } \\
\hline Han & $2113(67.16)$ & \\
\hline Yi & $365(11.60)$ & \\
\hline Wa & $103(3.27)$ & \\
\hline Others & $565(17.96)$ & \\
\hline \multicolumn{3}{|l|}{ Grade } \\
\hline Primary school & $1132(35.98)$ & \\
\hline Middle school & $1069(33.98)$ & \\
\hline High school & $945(31.04)$ & \\
\hline Age of father & & $42.27 \pm 5.02$ \\
\hline Age of mother & & $39.49 \pm 4.73$ \\
\hline \multicolumn{3}{|l|}{ Educational level of father } \\
\hline Primary school and below & $885(28.13)$ & \\
\hline Middle school & $1006(32.01)$ & \\
\hline High school or equivalent and above & $926(29.44)$ & \\
\hline Unknown & $245(7.79)$ & \\
\hline Missing & $84(2.67)$ & \\
\hline \multicolumn{3}{|l|}{ Educational level of mother } \\
\hline Primary school and below & $1077(34.23)$ & \\
\hline Middle school & $951(30.23)$ & \\
\hline High school or equivalent and above & $865(27.50 \%)$ & \\
\hline Unknown & $223(7.09)$ & \\
\hline Missing & $30(0.95)$ & \\
\hline CTQ & $36.03(9.59)$ & \\
\hline RSCA total & $95.52(17.73)$ & \\
\hline Goal concentration & & $17.21 \pm 5.09$ \\
\hline Interpersonal assistance & & $21.18 \pm 5.67$ \\
\hline Emotion regulation & & $21.14 \pm 5.65$ \\
\hline Positive perception & & $13.58 \pm 4.13$ \\
\hline Family support & & $22.42 \pm 4.71$ \\
\hline Self-harm behavior (Yes) & $1480(47.04 \%)$ & \\
\hline Self-harm level score & $10.18(20.59)$ & \\
\hline
\end{tabular}

Correlations between childhood maltreatment, resilience, and $\mathrm{SH}$

As illustrated in the correlation matrix (Fig. 1), the scores for CTQ, RSCA, and MASHS were significantly correlated with each other: resilience in general, together with all its 5 dimensions, were significantly inversely correlated with both $\mathrm{CM}$ and $\mathrm{SH}$, with correlation coefficients ranging from $-0.11(p<0.001)$ to $-0.56(p<$ 


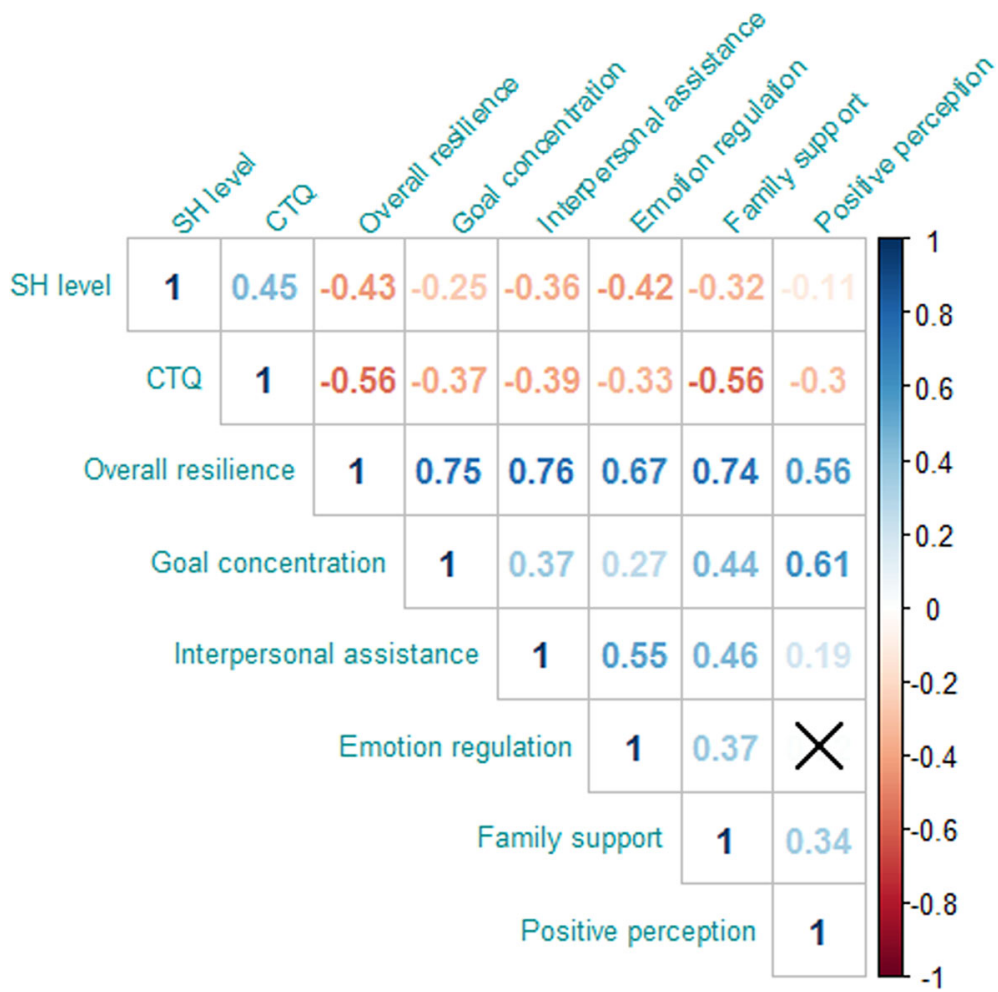

Fig. 1 Correlation matrix for childhood maltreatment (CTQ), resilience with five dimensions and SH levels. Note: SH, self-harm; $C T Q$, The childhood trauma questionnaire. All presenting correlation coefficients' $p$ values $<0.001$; ' $X$ ': $p>0.05$

0.001); a significant positive correlation was presented between CTQ score and MASHS score $(r=0.45, p<0.001)$.

\section{Moderation of resilience in $\mathrm{CM}-\mathrm{SH}$ association}

The results of hierarchical multivariate linear regression model were displayed in Table 2. Scores for CTQ, RSCA, MASHS were centered to weaken multicollinearity. CTQ and demographic variables (sex, age, grade, educational levels of mother) were entered in the first model; resilience was then added in in the second model; in the third model, the interaction term of CM and resilience was incorporated. The results indicated that, both $\mathrm{CM}$ and resilience were significantly associated with $\mathrm{SH}$. Moreover, it was found that the interaction between resilience and $\mathrm{CM}$ had a weak but significant association with $\mathrm{SH}$, which indicated that resilience served as a moderator in $\mathrm{CM}-\mathrm{SH}$ association: adolescents with lower resilience were found elevated $\mathrm{SH}$ scores under severer exposure of $\mathrm{CM}$, whereas for adolescents of higher resilience, individuals with severer CM had decreased SH scores (Fig. 2).

\section{Mediation of resilience in $\mathrm{CM}-\mathrm{SH}$ association}

The preceding results were indicative of a potential mediation by resilience in $\mathrm{CM}-\mathrm{SH}$ association, therefore we conducted structural equation modeling (SEM) to test this hypothesis. The hypothesized path model exhibited satisfactory fit to our data. As graphically presented in Fig. 3, CM was directly associated with resilience $(b=-$ $0.56, p<0.001)$ and SH level $(b=0.30, p<0.001)$, resilience was directly associated with $\mathrm{SH}$ level $(b=-0.27$, $p<0.001)$ and partially mediated the association between $\mathrm{CM}$ and $\mathrm{SH}$ (standardized indirect association $=-0.56^{*}$ $0.27=0.15$ ), which explained $33.46 \%$ of the total association (total association $=-0.56 *-0.27+0.30=0.45$ ).

Due to the identified significant mediation via the overall resilience, a group of additional mediation analyses were conducted for the five dimensions of resilience (goal concentration, interpersonal assistance, emotion regulation, family support, and positive perception), and the results were collectively summarized in Fig. 4: except for positive perception, which presented an insignificant association with $\mathrm{SH}$, all the other four dimensions were significant mediators in the association of CM-SH. Emotion regulation presented the most conspicuous mediation (23.14\%), followed by family support (19.08\%).

\section{Discussion}

In agreement with our anticipation, resilience may simultaneously mediate and moderate the association between childhood maltreatment and self-harm in Chinese 
Table 2 Hierarchical regression analyses for testing the moderation role of resilience

\begin{tabular}{|c|c|c|c|c|c|}
\hline Covariates & $\begin{array}{l}\text { Univariable } \\
\text { B }(95 \% \mathrm{Cl})\end{array}$ & $\begin{array}{l}p \\
\text { value }\end{array}$ & $\begin{array}{l}\text { Model } 1 \\
\text { B (95\% Cl) }\end{array}$ & $\begin{array}{l}\text { Model } 2 \\
\text { B }(95 \% \mathrm{Cl})\end{array}$ & $\begin{array}{l}\text { Model } 3 \\
\text { B }(95 \% \mathrm{Cl})\end{array}$ \\
\hline \multicolumn{6}{|l|}{ Sex (Ref: male) } \\
\hline Female & $3.64(1.29-5.98)$ & 0.014 & $4.28(2.34-6.22)$ & $3.63(1.96-5.24)$ & $2.88(1.42-4.34)$ \\
\hline Age $(+1)$ & $1.61(0.82-2.39)$ & 0.003 & $0.24(-0.68-1.16)$ & $0.03(-0.88-0.94)$ & $0.01(-0.07-0.80)$ \\
\hline \multicolumn{6}{|l|}{ Ethnicity (Ref: Other) } \\
\hline Han & $-0.39(-2.44-1.66)$ & 0.716 & - & - & - \\
\hline \multicolumn{6}{|l|}{ Grade (Ref: primary school) } \\
\hline Middle school & $6.88(2.89-10.87)$ & 0.009 & $6.84(2.90-10.79)$ & $6.89(3.53-10.25)$ & $6.50(3.12-9.88)$ \\
\hline High school & $8.68(3.72-13.64)$ & $<0.001$ & $8.80(1.26-16.34)$ & $8.80(1.84-15.76)$ & $8.19(1.80-14.58)$ \\
\hline Age of father (+ 1 year) & $0.17(-0.04-0.38)$ & 0.141 & - & - & - \\
\hline Age of mother(+ 1 year) & $0.15(-0.04-0.35)$ & 0.163 & - & - & - \\
\hline \multicolumn{6}{|c|}{ Educational level of father (Ref: primary school and below) } \\
\hline Middle school & $0.21(-1.32-1.75)$ & 0.793 & - & - & - \\
\hline High school or equivalent and above & $-1.67(-4.72-1.37)$ & 0.313 & - & - & - \\
\hline \multicolumn{6}{|c|}{ Educational level of mother (Ref: primary school and below) } \\
\hline Middle school & $-2.13(-4.00-0.25)$ & 0.016 & $0.34(-1.52-2.20)$ & $0.61(-1.04-2.26)$ & $0.43(-1.33-2.18)$ \\
\hline High school or equivalent and above & $-3.04(-6.24-0.16)$ & 0.099 & $2.18(0.11-4.24)$ & $2.96(1.13-4.80)$ & $2.30(0.43-4.18)$ \\
\hline CTQ & & & $1.02(0.77-1.26)$ & $0.71(0.55-0.86)$ & $0.42(0.30-0.55)$ \\
\hline $\operatorname{RSCA}(+5)$ & & & - & $-1.47(-1.93--1.01)$ & $-1.67(-2.11--1.23)$ \\
\hline CTQ*RSCA (+5) & & & - & - & $-0.10(-0.13--0.07)$ \\
\hline
\end{tabular}

Note: CTQ, The childhood trauma questionnaire; RSCA, The resilience scale for Chinese adolescents

adolescents: although the moderation was week, nearly one-third of the CM-SH association can be mediated via resilience. Besides, except for positive perception, all the rest 4 dimensions of resilience presented as prominent mediators, specifically, emotion regulation and family support showed the strongest mediation.

As hypothesized, resilience was identified as a prominent moderator in CM-SH association, although the moderation was weak, to be specific, a higher resilience of the victim tended to attenuate this association. Existing literature is supportive of the interaction between resilience and childhood trauma in predicting depression [20-22], the most significant risk factor for SH [6]. According to the theory proposed by Nock, SH emerges with the attempt to cope with adverse events [16]. As a defensive mechanism to cope with adversity, resilience is built on the integration of physical, psychological, social, and intellectual resources [23]. These resources consequently are helpful for an individual to cope with environmental stresses [24], like childhood maltreatment. Therefore, it is possible that highly resilient adolescents are more capable of acquiring and mobilizing these resources to help them antagonizing the negative influence of abusive or neglectful family environments. In previous studies, researchers also found that more resilient victims of negative life encounters reported less severe psychological problems or SH engagement [25-27].
Working with a sample of boarding undergraduate students, however, Madden and Shannon did not find resilience as a moderating variable in the association between $\mathrm{CM}$ and $\mathrm{SH}$ [28]. One possible explanation could be that the limited sample size $(N=285)$ hampers statistical efficiency in detecting significant relationship. Moreover, drawn from a residential school, participants in that research enjoyed more chances to seek assistance or consult from their roommates in coping with $\mathrm{CM}$, which may potentially reduce $\mathrm{SH}$ risk, as social support is considered a protective factor of $\mathrm{SH}$ among adolescents [29]. Future studies of larger sample sizes and longitudinal design are expected to further discuss this issue.

Another important finding is that, aside from moderation, resilience also presented as a strong mediator in $\mathrm{CM}-\mathrm{SH}$ association. Moreover, specific dimensions of resilience acted discordantly in this mediation, with emotion regulation emerged as the strongest mediator. Attachment theory suggests that growing up in attachment threatening environments, such as abusive or neglectful families, children can exhibit a propensity to suppress their feelings instead of confiding to their parents. The long-term suppression in mood may impose a detrimental effect on emotion regulatory function [30, 31]. Besides, given the fact that self-injurers always adopt $\mathrm{SH}$ as a method to vent negative 


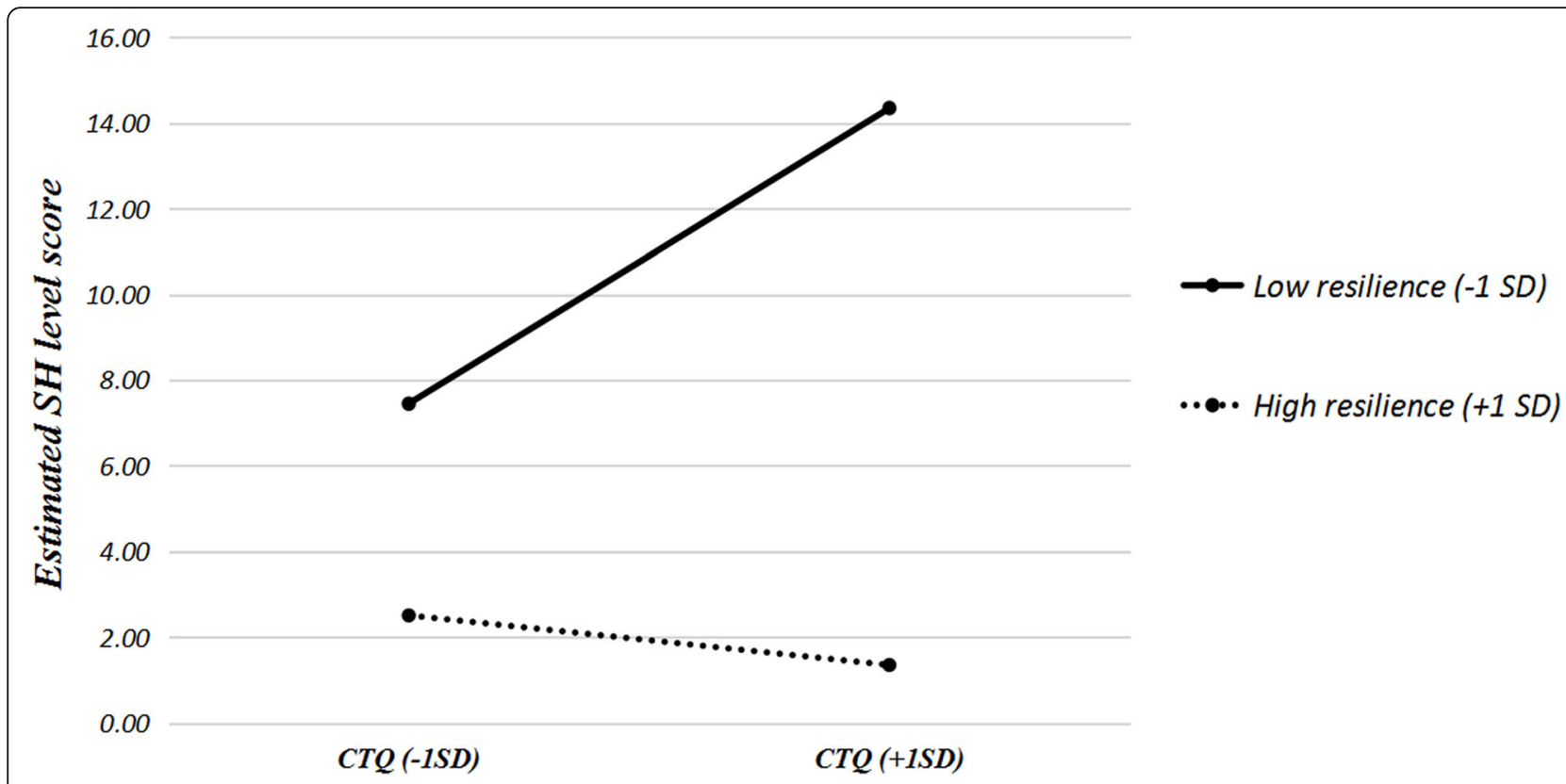

Fig. 2 The estimated SH level scores for adolescents who scored low (- 1 SD) vs. high (+ 1 SD) on CTQ and low (- 1 SD) vs. high (+ 1 SD) on RSCA. Note: SH, self-harm; CTQ, childhood trauma questionnaire, RSCA, The resilience scale for Chinese adolescents

feelings [32], it is reasonable that emotionally dysregulated young victims of family abuse or neglect may resort to SH. Besides, individuals with childhood traumatic experiences presented increased risk in developing disordered sensory processing patterns, such as low self-registration, sensory sensitivity, and sensation avoidance, all are related to increased risk of depression [33-36], a well-recognized and most important risk factor of $\mathrm{SH}$.

For other dimensions of resilience, family support and interpersonal assistance also showed conspicuous mediation in $\mathrm{CM}-\mathrm{SH}$ association. From an empirical perspective, it is a consensus that children experienced $\mathrm{CM}$ are more difficult in establishing secure parent-child attachments [37]. Insecure parent-child relationship can lead to lower levels of self-esteem, self-efficacy, and reflective functioning [38-40], all of which increase vulnerability to mental symptoms like depression in adolescence [41-43]. Moreover, school-aged children with intimate parent-child bonds tend to have lower presence,

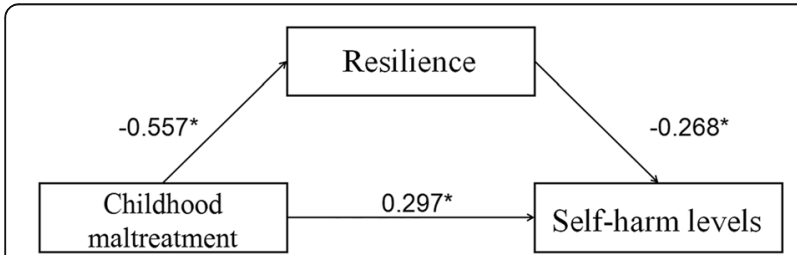

Fig. 3 SEM analysis of the indirect effect of childhood maltreatment on self-harm levels via resilience. Note: All path coefficients were standardized. ${ }^{*} p<0.01$ frequency, and severity of SH [44]. Prospective studies have identified a connection between childhood abuse and future dysfunctional social relationships and interpersonal problems [45]. Therefore, it is possible that victims of $\mathrm{CM}$ may be less willing to seek assistance from the others under stressful situations, which may in turn result in an increased risk of SH.

Our results shed new light on intervention strategies of $\mathrm{SH}$ in adolescents with $\mathrm{CM}$ experiences. On one hand, measures aiming at reinforcing emotion regulation ability among maltreated youths may be effective in curtailing SH. Two types of intervention that focusing on improving emotion dysregulation to antagonize $\mathrm{SH}$ have been developed in clinical practice, one is dialectical behavior therapy, the other is acceptance-based emotion regulation group therapy. Besides, a telephone-based therapy has been found effective in positive emotion regulation among patients with bipolar depression [46, 47]. On the other hand, as both family support and interpersonal assistance are primary sources of social support, enhancing social support might be another promising direction in preventing $\mathrm{CM}$ associated $\mathrm{SH}$ among teenagers. At first, problem-solving therapy from which individuals can learn how to seek interpersonal assistance might be beneficial, as such therapy has been proved effective in reducing helplessness and suicidal ideation in depressive patients, though in small-sized samples [48]. However, evidence from a large pragmatic trial recommended problem-solving therapy as an alternative only for patients with repeated $\mathrm{SH}$ attempt [49]. Moreover, promoting positive comprehension of family 


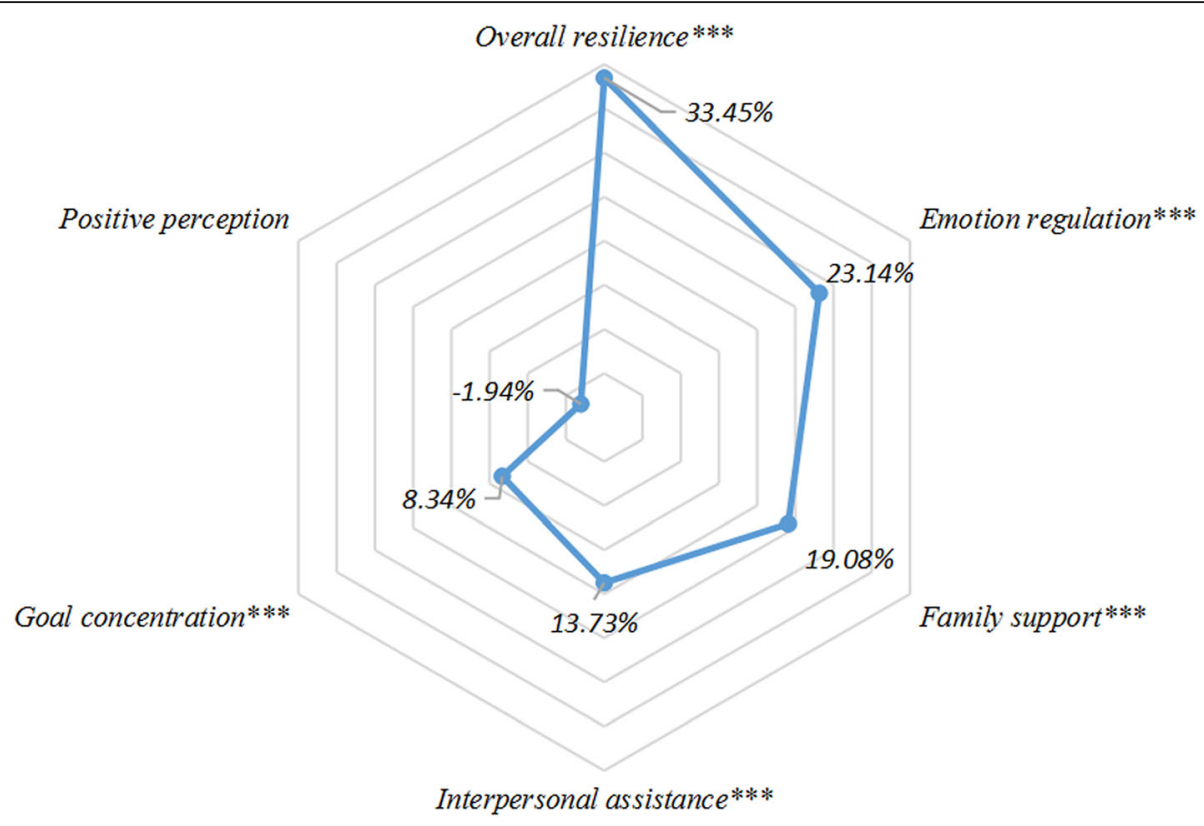

Fig. 4 The mediating effect percentages of resilience with five dimensions on the relationship between childhood maltreatment and self-harm levels. ${ }^{* * *} p<0.001$

support can also be considered, as an interventional study has proved its effectiveness among Chinese adolescents from impoverished areas [50].

Our study is among the first to test the moderating and mediating effect of resilience in the association between $\mathrm{CM}$ and $\mathrm{SH}$ in a large sample of Chinese adolescents. However, several limitations should be noticed. First, the cross-sectional nature prevents causal conclusions. Second, self-reported questionnaires are prone to information bias. Third, study subjects were chosen from a single province in southwest China, therefore a limit should be set for the generalization of study results. Future studies with expanded sampling sources and prospective design are warranted.

\section{Conclusion}

In this cross-sectional study of Chinese adolescents, we found that childhood maltreatment was prominently associated with $\mathrm{SH}$, besides, resilience exhibited significant moderation and mediation in $\mathrm{CM}-\mathrm{SH}$ association. Among all dimensions of resilience, emotion regulation, family support and interpersonal assistance emerged as the strongest mediators. The present study offers new perspectives for the prevention of $\mathrm{CM}$ related $\mathrm{SH}$ among Chinese adolescents: measures for strengthening psychological resilience, especially for improving emotion regulation ability, consolidating family support and interpersonal assistance should be considered in reducing the risk of $\mathrm{SH}$ among adolescent CM victims.

\section{Abbreviations}

CM: Childhood maltreatment; SH: Self-harm; CTQ: Childhood Trauma Questionnaire; RSCA: The Resilience Scale for Chinese Adolescents; MASHS: The Modified version of Adolescents Self-Harm Scale

\section{Acknowledgments}

Not applicable.

\section{Authors' contributions}

$X T$ and $J L$ performed data sorting and analyzing. XH, YC, DF, HR, YW, TW, XX, GY carried out data collection. XT wrote the first draft of the manuscript. YX critically revised the manuscript. All the authors commented on previous versions of the manuscript and read and approved the final manuscript.

\section{Funding}

The study was funded by National Natural Science Foundation of China (82060601), Top Young Talents of Yunnan Ten Thousand Talents Plan (YNWR-QNBJ-2018-286), Innovative Research Team of Yunnan Province (202005AE160002), NHC Key Laboratory of Drug Addiction Medicine (2020DAMARA-006), Yunnan Health Training Projects of Highly Level Talents (D-2017048), Scientific Research Fund Project of Yunnan Provincial Department of Education (2018JS198). The funding body in this study had no role in the design of the study and collection, analysis, and interpretation of data and in writing the manuscript.

\section{Availability of data and materials}

The datasets used and/or analyzed during the current study are available from the corresponding author on reasonable request.

\section{Declarations}

\section{Ethics approval and consent to participate}

This study was approved by the Ethics Committee of The Third People's Hospital of Lincang (Lincang Psychiatry Hospital). Written informed consents were obtained from the participants and their legal guardians.

Consent for publication

Not applicable. 


\section{Competing interests}

The authors declare that they have no competing interests.

\section{Author details}

'Department of Epidemiology and Health Statistics, School of Public Health, Kunming Medical University, Kunming 650500, Yunnan, China. ${ }^{2}$ The First Affiliated Hospital of Kunming Medical University, Kunming, Yunnan, China. ${ }^{3} \mathrm{NHC}$ Key Laboratory of Drug Addiction Medicine, The First Affiliated Hospital of Kunming Medical University, Kunming, China. ${ }^{4}$ Lincang Psychiatry Hospital, Lincang, Yunnan, China.

Received: 7 January 2021 Accepted: 12 July 2021

Published online: 17 August 2021

\section{References}

1. Gilbert R, Widom CS, Browne K, Fergusson D, Webb E, Janson S. Burden and consequences of child maltreatment in high-income countries. Lancet. 2009;373(9657):68-81. https://doi.org/10.1016/S0140-6736(08)61706-7.

2. Cai Q. Investigation on primary and middle school students' child abuse status and influence factors in Zhuang nationality area. master. Nanning: Guangxi Med Univ; 2009 (In Chinese).

3. Hussey JM, Chang JJ, Kotch JB. Child maltreatment in the United States: prevalence, risk factors, and adolescent health consequences. Pediatrics. 2006:118(3):933-42. https://doi.org/10.1542/peds.2005-2452.

4. Nock NK, Joiner TE, Gordon KH, Lloyd-Richardson E, Prinstein MJ. Nonsuicidal self-injury among adolescents: diagnostic correlates and relation to suicide attempts. Psychiatry Res. 2016;144:65-72.

5. Brezo J, Paris J, Vitaro F, Hebert M, Tremblay RE, Turecki G. Predicting suicide attempts in young adults with histories of childhood abuse. Br J Psychiatry. 2008;193(2):134-9. https://doi.org/10.1192/bjp.bp.107.037994.

6. Hawton K, Saunders KE, O'Connor RC. Self-harm and suicide in adolescents. Lancet. 2012;379(9834):2373-82. https://doi.org/10.1016/S0140-6736(12 60322-5.

7. Wan Y, Hu C, Hao J, Sun Y, Tao F. Deliberate self-harm behaviors in Chinese adolescents and young adults. Eur Child Adolesc Psychiatry. 2011;20(10): 517-25. https://doi.org/10.1007/s00787-011-0213-1.

8. Patton GC, Coffey C, Sawyer SM, Viner RM, Haller DM, Bose K, et al. Global patterns of mortality in young people: a systematic analysis of population health data. Lancet. 2009;374(9693):881-92. https://doi.org/10.1016/S01406736(09)60741-8

9. Owens D, Horrocks J, House A. Fatal and non-fatal repetition of self-harm. Systematic review. Br J Psychiatry. 2002;181(3):193-9. https://doi.org/10.11 92/bjp.181.3.193.

10. Coope C, Donovan J, Wilson C, Barnes M, Metcalfe C, Hollingworth W, et al. Characteristics of people dying by suicide after job loss, financial difficulties and other economic stressors during a period of recession (2010-2011): a review of coroners' records. J Affect Disord. 2015;183:98-105. https://doi. org/10.1016/j.jad.2015.04.045.

11. Dube SR, Anda RF, Felitti VJ, Chapman DP, Williamson DF, Giles WH. Childhood abuse, household dysfunction, and the risk of attempted suicide throughout the life span: findings from the adverse childhood experiences study. JAMA. 2001;286(24):3089-96. https://doi.org/10.1001/jama.286.24.3089.

12. Serafini G, Canepa G, Adavastro G, Nebbia J, Belvederi Murri M, et al. The relationship between childhood maltreatment and non-suicidal self-injury: a systematic review. Front Psych. 2017;24:149.

13. Fergus S, Zimmerman MA. Adolescent resilience: a frame work for understanding healthy development in the face of risk. Annu Rev Public Health. 2005;26(1):399-419. https://doi.org/10.1146/annurev.publhealth.26. 021304.144357.

14. Meng X, Fleury MJ, Xiang YT, Li M, D'Arcy C. Resilience and protective factors among people with a history of child maltreatment: a systematic review. Soc Psychiatry Psychiatr Epidemiol. 2018;53(5):453-75. https://doi. org/10.1007/s00127-018-1485-2.

15. Bolger KE, Patterson CJ. Sequelae of child maltreatment: vulnerability and resilience. Resilience and vulnerability: adaptation in the context of childhood adversities. Cambridge: Cambridge University Press; 2003. p. 156-81.

16. Nock MK, Prinstein MJ. Contextual features and behavioral functions of selfmutilation among adolescents. J Abnorm Psychol. 2005;114(1):140-6. https://doi.org/10.1037/0021-843X.114.1.140.
17. Bernstein DP, Stein JA, Newcomb MD, Walker E, Pogge D, Ahluvalia T, et al. Development and validation of a brief screening version of the childhood trauma questionnaire. Child Abuse Negl. 2003;27(2):169-90. https://doi.org/1 0.1016/S0145-2134(02)00541-0.

18. Hu Y, Gan Y. Development and psychometric validity of the resilience scale for Chinese adolescents. Acta Psychol Sin. 2008;40(8):902-12 (In Chinese). https://doi.org/10.3724/SP.J.1041.2008.00902.

19. Feng $Y$. The relation of adolescents' self-harm behaviors, individual emotion characteristics and family environment factors. master. Wuhan: Central China Norm Univ; 2008 (In Chinese).

20. Campbell-Sills L, Cohan SL, Stein MB. Relationship of resilience to personality, coping, and psychiatric symptoms in young adults. Behav Res Ther. 2006;44(4):585-99. https://doi.org/10.1016/j.brat.2005.05.001.

21. Ding H, Han J, Zhang M, Wang K, Gong J, Yang S. Moderating and mediating effects of resilience between childhood trauma and depressive symptoms in Chinese children. J Affect Disord. 2017;211:130-5. https://doi. org/10.1016/j.jad.2016.12.056.

22. Wingo AP, Wrenn G, Pelletier T, Gutman AR, Bradley B, Ressler KJ. Moderating effects of resilience on depression in individuals with a history of childhood abuse or trauma exposure. J Affect Disord. 2010;126(3):411-4. https://doi.org/10.1016/j.jad.2010.04.009.

23. Tugade MM, Fredrickson BL. Resilient individuals use positive emotions to bounce back from negative emotional experiences. J Pers Soc Psychol. 2004;86(2):320-33. https://doi.org/10.1037/0022-3 514.86.2.320.

24. Rew L, Horner SD. Youth resilience framework for reducing health-risk behaviours in adolescents. J Pediatr Nurs. 2003;18(6):379-88. https://doi. org/10.1016/S0882-5963(03)00162-3.

25. Peng L, Zhang J, Li M, Li P, Zhang Y, Zuo X, et al. Negative life events and mental health of Chinese medical students: the effect of resilience, personality and social support. Psychiatry Res. 2012;196(1):138-41. https:// doi.org/10.1016/j.psychres.2011.12.006.

26. Tian X, Chang W, Meng Q, Chen Y, Yu Z, He L, et al. Resilience and selfharm among left-behind children in Yunnan, China: a community-based survey. BMC Public Health. 2019;19:1728.

27. Shi J, Chen Z, Yin F, Zhao J, Zhao X, Yao Y, Resilience as moderator of the relationship between left-behind experience and mental health of Chinese adolescents. Int J Soc Psychiatry. 2016;62(4):386-93. https://doi.org/10.1177/ 0020764016636910

28. Madden SC. The relationship between psychological maltreatment and deliberate self-harm and the moderating role of resilience in an undergraduate residence hall population. doctor. North Carolina: University of North Carolina; 2007.

29. Deliberto TL, Nock MK. An exploratory study of correlates, onset, and offset of non-suicidal self-injury. Arch Suicide Res. 2008;12(3):219-31. https://doi. org/10.1080/13811110802101096

30. Mikulincer M, Shaver PR, Pereg D. Attachment theory and affect regulation: the dynamics, development, and cognitive consequences of attachmentrelated strategies. Motiv Emot. 2003;27(2):77-102. https://doi.org/10.1023/A:1 024515519160 .

31. Morris AS, Silk JS, Steinberg L, Myers SS, Robinson LR. The role of the family context in the development of emotion regulation. Soc Dev. 2010:16:361-88.

32. Messer JM, Fremouw WJ. A critical review of explanatory models for selfmutilating behaviors in adolescentss. Clin Psychol Rev. 2008;28(1):162-78. https://doi.org/10.1016/j.cpr.2007.04.006.

33. Kim J, Cicchetti D. Longitudinal pathways linking child maltreatment, emotion regulation, peer relations, and psychopathology. J Child Psychol Psychiatry. 2010;51(6):706-16. https://doi.org/10.1111/j.1469-7610.2009.02202.x.

34. Jennissen S, Holl J, Mai H, Wolff S, Barnow S. Emotion dysregulation mediates the relationship between child maltreatment and psychopathology: a structural equation model. Child Abuse Negl. 2016;62:51-62. https://doi.org/10.1016/j.chiabu.2016.10.015.

35. Crow T, Cross D, Powers A, Bradley B. Emotion dysregulation as a mediator between childhood emotional abuse and current depression in a lowincome African-American sample. Child Abuse Negl. 2014;38(10):1590-8. https://doi.org/10.1016/j.chiabu.2014.05.015.

36. Serafini G, Gonda X, Pompili M, Rihmer Z, Amore M, Engel-Yeger B. The relationship between sensory processing patterns, alexithymia, traumatic childhood experiences, and quality of life among patients with unipolar and bipolar disorders. Child Abuse Negl. 2016;62:39-50. https:/doi.org/10.1016/..chiabu.2016.09.013. 
37. Youngblade LM, Belsky J. Child maltreatment, infant-parent attachment security, and dysfunctional peer relationships in toddlerhood. Top Early Child Spec Educ. 1989;9(2):1-15. https://doi.org/10.1177/027112148900900202.

38. Arbona C, Power T. Parental attachment, self-esteem, and antisocial behaviors among African American, European American, and Mexican American adolescents. J Couns Psychol. 2003;50(1):40-51. https://doi.org/1 0.1037/0022-0167.50.1.40.

39. Cassidy J, Shaver PR. Handbook of attachment: Theory, research, , and clinical applications. 3rd ed. New York: Guilford Press; 2016.

40. Borelli JL, Compare A, Snavely JE, Decio V. Reflective functioning moderates the association between perceptions of parental neglect and attachment in adolescence. Psychoanal Psychol. 2015;32(1):23-35. https//doi.org/10.1037/a0037858.

41. Guerra C, Farkas C, Moncada L. Depression, anxiety and PTSD in sexually abused adolescents: association with self-efficacy, coping and family support. Child Abuse Negl. 2018;76:310-20. https:/doi.org/10.1016/..chiabu.2017.11.013.

42. Sowislo JF, Orth U. Does low self-esteem predict depression and anxiety? A meta-analysis of longitudinal studies. Psychol Bull. 2013;139(1):213-40. https://doi.org/10.1037/a0028931.

43. Borelli JL, Brugnera A, Zarbo C, Rabboni M, Bondi E, Tasca GA, et al. Attachment comes of age: adolescents' narrative coherence and reflective functioning predict well-being in emerging adulthood. Attach Hum Dev. 2019;21(4):332-51. https:/doi. org/10.1080/14616734.2018.1479870.

44. Wang $\mathrm{Y}$, Zhang $\mathrm{M}$, Chen $\mathrm{H}$. Self-injuny among left-behind adolescents in rural China: the role of parental migration and parent-child attachment. Front Psychol. 2019;9: 2672. https://doi.org/10.3389/ppsyg.2018.02672.

45. Colman RA, Widom CS. Childhood abuse and neglect and adult intimate relationships: a prospective study. Child Abuse Negl. 2004;28(11):1133-51. https://doi.org/10.1016/j.chiabu.2004.02.005.

46. Gratz KL. Targeting emotion dysregulation in the treatment of self-injury. J Clin Psychol. 2007;63(11):1091-103. https://doi.org/10.1002/jclp.20417.

47. Celano CM, Gomez-Bernal F, Mastromauro CA, Beale EE, DuBois CM, Auerbach RP, et al. A positive psychology intervention for patients with bipolar depression: a randomized pilot trial. J Ment Health. 2020; 29(1):60-8. https://doi.org/10.1080/09638237.2018.1521942.

48. Townsend E, Hawton K, Altman DG, Arensman E, Gunnell D, Hazell $P$, et al. The efficacy of problem-solving treatments after deliberate self-harm: meta-analysis of randomized controlled trials with respect to depression, hopelessness and improvement in problems. Psychol Med. 2001;31(6):979-88. https://doi.org/10.1017/S0033291701004238.

49. Hatcher S, Sharon C, Parag V, Collins N. Problem-solving therapy for people who present to hospital with self-harm: Zelen randomised controlled trial. Br J Psychiatry. 2011;199(4):310-6. https://doi.org/1 0.1192/bjp.bp.110.090126.

50. Niu Y. An intervention research on the relationship between psychological resilience and perceived social support among left-behind children. master. Nanjing: Nanjing Norm Univ; 2014 (In Chinese).

\section{Publisher's Note}

Springer Nature remains neutral with regard to jurisdictional claims in published maps and institutional affiliations.

Ready to submit your research? Choose BMC and benefit from:

- fast, convenient online submission

- thorough peer review by experienced researchers in your field

- rapid publication on acceptance

- support for research data, including large and complex data types

- gold Open Access which fosters wider collaboration and increased citations

- maximum visibility for your research: over $100 \mathrm{M}$ website views per year

At BMC, research is always in progress.

Learn more biomedcentral.com/submissions 